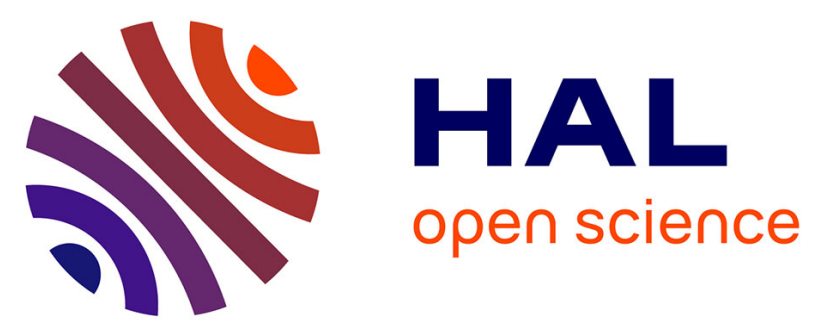

\title{
Evaluation of temoporfin affinity to $\beta$-cyclodextrins assuming self-aggregation
}

\author{
Ilya Yakavets, Henri-Pierre Lassalle, Igor Yankovsky, Francesca Ingrosso, A. \\ Monari, Lina Bezdetnaya, Vladimir Zorin
}

\section{- To cite this version:}

Ilya Yakavets, Henri-Pierre Lassalle, Igor Yankovsky, Francesca Ingrosso, A. Monari, et al.. Evaluation of temoporfin affinity to $\beta$-cyclodextrins assuming self-aggregation. Journal of Photochemistry and Photobiology A: Chemistry, 2018, 367, pp.13-21. 10.1016/j.jphotochem.2018.07.046 . hal-01861135

\section{HAL Id: hal-01861135 https://hal.science/hal-01861135}

Submitted on 21 Jan 2022

HAL is a multi-disciplinary open access archive for the deposit and dissemination of scientific research documents, whether they are published or not. The documents may come from teaching and research institutions in France or abroad, or from public or private research centers.
L'archive ouverte pluridisciplinaire HAL, est destinée au dépôt et à la diffusion de documents scientifiques de niveau recherche, publiés ou non, émanant des établissements d'enseignement et de recherche français ou étrangers, des laboratoires publics ou privés.

\section{(ㅇ)(1) $\$$}

Distributed under a Creative Commons Attribution - NonCommercial - NoDerivatives| 4.0 


\section{EVALUATION OF TEMOPORFIN AFFINITY TO $\beta$-CYCLODEXTRINS ASSUMING SELF-AGGREGATION}

Yakavets I. ${ }^{1,2,3}$, Lassalle H.-P. ${ }^{2,3}$, Yankovsky I. ${ }^{1}, \quad$ Ingrosso F. ${ }^{4}, \quad$ Monari A. ${ }^{4}, \quad$ Bezdetnaya L ${ }^{2,3}$, Zorin V. ${ }^{1,5^{*}}$

${ }^{1}$ Laboratory of Biophysics and Biotechnology, Physics Faculty, Belarusian State University, Minsk, Belarus. (yakavetsiv@bsu.by, yankovsky@bsu.by, vpzorin@bsu.by)

${ }^{2}$ Université de Lorraine, CNRS, CRAN, F-54000 Nancy, France. (ilya.yakavets@univ-lorraine.fr, henripierre.lassalle@univ-lorraine.fr, lina.bolotine@univ-lorraine.fr)

${ }^{3}$ Université de Lorraine, CHRU-Nancy, Institut de Cancérologie de Lorraine, F-54000, France. (i.yakavets@nancy.unicancer.fr, h.lassalle@nancy.unicancer.fr, 1.bolotine@nancy.unicancer.fr)

${ }^{4}$ Université de Lorraine, CNRS, LPCT, F-54000 Nancy, France. (francesca.ingrosso@univ-lorraine.fr, antonio.monari@univ-lorraine.fr)

${ }^{5}$ International Sakharov Environmental Institute, Minsk, Belarus. (vpzorin@bsu.by)

*Correspondance: Vladimir Zorin. Laboratory of Biophysics and Biotechnology, Physics Faculty, Belarusian State University, 4 Nezavisimosti Ave, 220030, Minsk, Belarus. Tel: +375 175983 53; Fax: + 3751722659 40. Institutional E-mail: vpzorin@bsu.by; Personal e-mail:vpzorin@mail.ru

\section{Graphical abstract}




\title{
High affinity of CDs to mTHPC could be prerequisite for effective mTHPC delivery
}

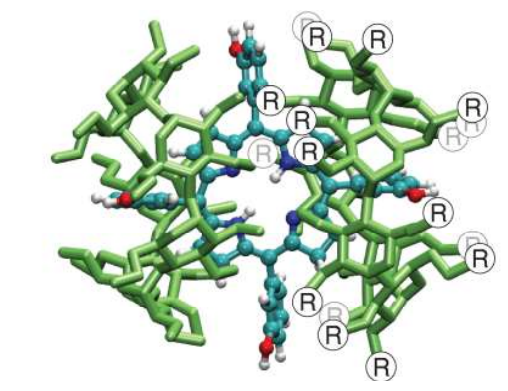

Hp- $\beta$-CD: $\mathrm{R}=\mathrm{H}_{21-\mathrm{m}}$ or $\left(\mathrm{CH}_{2}(\mathrm{CHOH}) \mathrm{CH}_{3}\right)_{m}$ Me- $\beta$-CD: $\mathrm{R}=\mathrm{H}_{21-\mathrm{m}}$ or $\left(\mathrm{CH}_{3}\right)_{\mathrm{m}}$ TM- $\beta-C D: ~ R=\mathrm{CH}_{3}$

\section{Hp- $\beta$-CD Me- $\beta-C D$ TM- $\beta-C D$ \\ Apparent binding constant $\quad 4.5 \times 10^{4} \mathrm{M}^{-1} \quad 3.0 \times 10^{5} \mathrm{M}^{-1} \quad 5.6 \times 10^{6} \mathrm{M}^{-1}$ \\ without assuming aggregation $\begin{array}{r}\text { "Correct" binding constant } \\ \text { assuming aggregation }\end{array} \quad 17 \times 10^{4} \mathrm{M}^{-1} \quad 7.1 \times 10^{5} \mathrm{M}^{-1} \quad \mathbf{1 1 \times 1 0 ^ { 6 }} \mathbf{M}^{-1}$}

Porhyrin self-aggregation hides strong $\beta$-CDs affinity to $M T H P C$

\section{Highlights}

- $\quad$ mTHPC easily forms 1:2 inclusion complexes with $\beta$-CDs following 2 step mechanism.

- Methylation of $\beta$-CD's core enhances the affinity to mTHPC

- mTHPC aggregation reduce the binding constant of the first $\beta$-CD molecule

- Corrected binding constant values are several times higher than previously reported

- High binding constants allow the use the $\beta$-CDs for mTHPC delivery in PDT

\begin{abstract}
The interaction between the potent photosensitizer meta-tetrakis(3-hydroxyphenyl)chlorin (temoporfin, mTHPC) and a series of $\beta$-cyclodextrins ( $\beta$-CDs) was investigated using spectroscopic analysis and molecular dynamics simulations. The possibility of improving its poor aqueous solubility with $\beta$-CDs was estimated by measuring both equilibrium solubility and association constants. Parameters of binding isotherms revealed that mTHPC strongly interacts with $\beta$-CD derivatives, forming 1:2 inclusion complexes in aqueous solution. We demonstrated that apparent binding constants strongly
\end{abstract}


depend on mTHPC concentration due to the porphyrin self-aggregation. The estimated "correct" binding constants demonstrated that completely methylated $\beta$-CD exhibits the highest affinity $\left(\mathrm{K}=1.1 \times 10^{7} \mathrm{M}^{-1}\right)$ as compared to randomly methylated $\beta-\mathrm{CD}\left(\mathrm{K}=7.1 \times 10^{5} \mathrm{M}^{-1}\right)$ and 2-hydroxypropyl substituted $\beta$-CD $\left(\mathrm{K}=1.7 \times 10^{5} \mathrm{M}^{-1}\right)$. In fine, our results indicate that $\mathrm{TM}-\beta-\mathrm{CD}$ should be considered as a potent vector for mTHPC targeted delivery.

\section{Keywords}

Supramolecular chemistry; $\beta$-cyclodextrins; mTHPC; binding constants; aggregation; circular dichroism.

\section{Introduction}

Meta-tetrakis(3-hydroxyphenyl)chlorin (mTHPC, temoporfin) is one of the most potent clinically approved photosensitizer (PS) for the photodynamic therapy (PDT) of head and neck cancers [1,2]. mTHPC molecules are highly hydrophobic and are prone to aggregation in biological media, resulting in decreased photodynamic efficacy, moderate selectivity and prolonged skin photosensitivity [1,3]. Various attempts are being made to use special drug delivery and formulations of mTHPC in order to prevent aggregation and improve its pharmacokinetic properties. The use of several nanosized systems for mTHPC delivery (liposomes, polymeric vesicles, dendrimers etc.) demonstrated a significant improvement in its bioavailability, biodistribution and photosensitizing activity.

Cyclic oligosaccharides such as $\beta$-cyclodextrins ( $\beta$-CDs) are promising delivery systems for different nonpolar drugs including aryl-substituted porphyrin PSs [4-7]. It was reported, that $\beta$-CDs readily interact with $\mathrm{mTHPC}$ incorporating drug molecule or its part in the inner hydrophobic cavity [8]. The formation of inclusion complexes increases mTHPC solubilization and recovers its photophysical 
properties. According to our recent study, $\beta$-CDs significantly modify in vitro and in vivo biodistribution of mTHPC, in particular inhibiting mTHPC aggregation and hence accelerating PS transportation by serum proteins, ultimately increasing PS accumulation at the target sites [7,9]. However, despite the growing amount of information on the interaction of porphyrins and other dyes with $\beta$-CDs, a detailed study unravelling the molecular bases of the host-guest complex formation in the context of PS pharmacokinetics alteration is still missing. It is obvious that the ability of cyclodextrins to favorably alter PS biodistribution is mainly determined by the values of their association constants $[7,10,11]$.

The complex formation of mTHPC with 2-hydroxypropyl- $\beta$-cyclodextrin (HP- $\beta$-CD) and random methyl- $\beta$-cyclodextrin $(\mathrm{Me}-\beta-\mathrm{CD})$ was reported earlier $[8,12,13]$, however the results were rather contradictionary. The interaction of heptakis(2,3,6-tri-O-methyl)- $\beta$-cyclodextrin (TM- $\beta$-CD) with mTHPC was not studied yet, still it would be of big interest since as was pointed out by Kano et al., (2002) [14], a highly hydrophobic cavity of complete methylated $\beta$-CD could enhance the affinity to aryl-porphyrins. In this respect, the determination of exact binding constants is of fundamental value allowing the rationalization and prediction of $\beta$-CDs effects on drug distribution in complex biological systems.

The present work aims to estimate the association constants between mTHPC and several $\beta$-CD derivatives (Scheme 1) taking into account the impact of physical-chemical factors including porphyrins aggregation. We used Induced Circular Dichroism (ICD) and fluorescence techniques to assess the formation of the complexes between mTHPC and $\beta$-CDs, with the successive analysis of the results by a rather complex nonlinear mathematical model. 
A

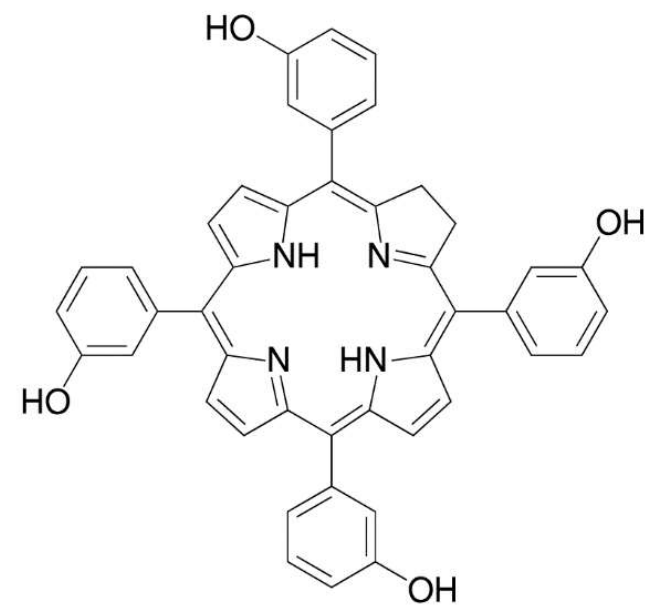

meta-tetrakis(3-hydroxyphenyl)chlorin
B

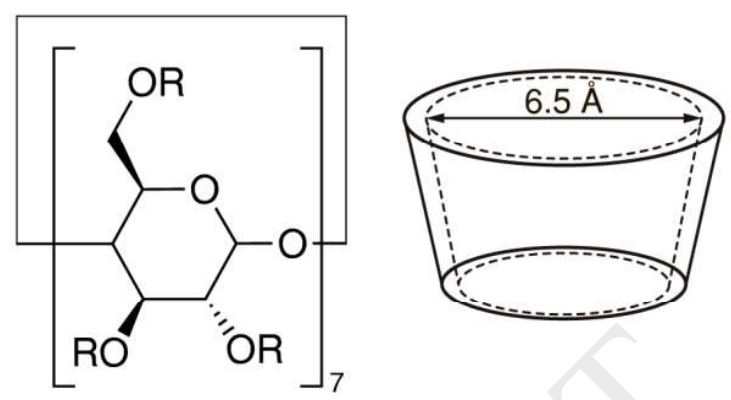

$\mathrm{Hp}-\beta-\mathrm{CD}: \mathrm{R}=\mathrm{H}_{21-\mathrm{m}}$ or $\left(\mathrm{CH}_{2}(\mathrm{CHOH}) \mathrm{CH}_{3}\right)_{m}$ Me- $\beta$-CD: $\mathrm{R}=\mathrm{H}_{21-\mathrm{m}}$ or $\left(\mathrm{CH}_{3}\right)_{\mathrm{m}}$ TM- $\beta-C D: R=\mathrm{CH}_{3}$

$\beta$-cyclodextrin derivatives

Scheme 1. Molecular structures of (A) mTHPC and (B) $\beta$-CD derivatives. The degree of substitution (DS) is given by the m values, reported in the experimental section.

\section{Material and methods}

\subsection{Materials}

The photosensitizer mTHPC was kindly provided by biolitec research GmbH (Jena, Germany) with the purity $>99 \%$. The cyclodextrins Me- $\beta-\mathrm{CD}$ (purity $>98 \%$, DS = 11-14, average M.W. $1310 \mathrm{Da}$ ), TM- $\beta$-CD (purity $>98 \%$, M.W. $1430 \mathrm{Da}$ ) and Hp- $\beta-\mathrm{CD}$ (purity $>98 \%$, DS = 3.5-5.5, average M.W. $1380 \mathrm{Da}$ ) were purchased from AraChem (Tilburg, the Netherlands). $\beta$-CDs in powder were weighted and then dissolved in Dulbecco's phosphate-buffered saline (DPBS) (pH 7.4) at $4{ }^{\circ} \mathrm{C}$ at the final concentration of $20 \mathrm{mM}$ using molar weight provided by the supplier. mTHPC stock solution ( $1 \mathrm{mM})$ was prepared in absolute ethanol $(99.6 \%)$ and was kept at $4{ }^{\circ} \mathrm{C}$ in the dark. mTHPC concentration in the 
solution and the extinction coefficients were estimated by means of a spectrophotometric method using molar extinction coefficient of $30,000 \mathrm{M}^{-1} \mathrm{~cm}^{-1}$ at $650 \mathrm{~nm}$ in ethanol [15].

Inclusion complexes between $\beta$-CDs and mTHPC were formed using the co-precipitation method reported in details in [16]. Briefly, stock ethanol solution of mTHPC (1 mM) was added to $\beta$-CDs dissolved in DPBS (pH 7.4) at $4{ }^{\circ} \mathrm{C}$ at the required concentrations. The final content of ethanol in the mTHPC/ $\beta$-CD solutions did not exceed $0.5 \%$. The solution was thoroughly mixed for 15 min under magnetic stirring and was recorded after at least 2 hours of incubation.

\section{$1.2 \quad$ Spectroscopic measurements}

The absorption spectra were measured on Solar PV1251 (Solar, Belarus) spectrophotometer using $1 \mathrm{~cm}$ optical path quartz cuvettes. Fluorescent measurements were performed on Solar CM 2303 (Solar, Belarus) fluorescence spectrometer equipped with thermostat cuvette compartment and magnetic stirring. ICD spectra were recorded on a Chirascan-plus qCD (Applied Photophysics Limited, Surrey, United Kingdom) also equipped with thermostat cuvette compartment and magnetic stirring. The error in the wavelength measurements was estimated as $\pm 1 \mathrm{~nm}$. All spectroscopic measurements were carried out in triplicate at room temperature $\left(23-25^{\circ} \mathrm{C}\right)$. Optical density of all samples did not exceed 0.4 a.u.

The fluorescence quantum yields of mTHPC in complexes were determined using mTHPC solution in methanol, regarded as standard (fluorescence quantum yield is equal to 0.089 [15]). The fluorescence was excited at $416 \mathrm{~nm}$. The absolute error in quantum yields values was estimated as \pm 0.01 .

\section{$1.3 \quad$ Mathematical fitting}

The binding isotherms were fitted with a MATLAB software (The Math Works, USA), using mathematical binding models (Equation 1-4), which was previously described by Thordarson [17]. For optimization of the fit conditions, iterations were carried out until the difference in the value of chisquare for successive iterations did not exceed $5 \%$ of the previous value. To estimate the values beyond the original observation range, the mathematical extrapolation was used. The curves were 
mathematically extrapolated on the basis of experimental data in the range of mTHPC concentration $10 \mathrm{nM}-3 \mu \mathrm{M}$ using cubic spline algorithm (spline) as a basic function of Origin software (OriginLab, USA). The "correct" values of $\mathrm{K}_{11}$ binding constants were calculated at $0.1 \mathrm{nM}$.

$$
\Delta \mathrm{Y}=\left(\mathrm{Y}_{\Delta 0}+\mathrm{Y}_{\Delta 1: 1} \mathrm{~K}_{11}[\mathrm{CD}]\right) /\left(1+\mathrm{K}_{11}[\mathrm{CD}]\right)
$$

Equation 1. Mathematical model for one-step 1:1 binding

$$
\Delta \mathrm{Y}=\left(\mathrm{Y}_{\Delta 0}+\mathrm{Y}_{\Delta 1: 2} \mathrm{~K}_{12}[\mathrm{CD}]^{2}\right) /\left(1+\mathrm{K}_{12}[\mathrm{CD}]^{2}\right)
$$

Equation 2. Mathematical model for one-step 1:2 binding

$$
\Delta \mathrm{Y}=\left(\mathrm{Y}_{\Delta 0}+\mathrm{Y}_{\Delta 1: 1} \mathrm{~K}_{11}[\mathrm{CD}]+\mathrm{Y}_{\Delta 1: 2} \mathrm{~K}_{12}[\mathrm{CD}]^{2}\right) /\left(1+\mathrm{K}_{11}[\mathrm{CD}]+\mathrm{K}_{12}[\mathrm{CD}]^{2}\right)
$$

Equation 3. Mathematical model for two-step 1:2 binding

$$
[\mathrm{CD}]^{3}(\mathrm{~A})+[\mathrm{CD}]^{2}(\mathrm{~B})+[\mathrm{CD}](\mathrm{C})+[\mathrm{CD}]_{0}=0
$$

With:

$$
\begin{aligned}
& \mathrm{A}=\mathrm{K}_{11} \mathrm{~K}_{12} \\
& \mathrm{~B}=\mathrm{K}_{11}\left(2 \mathrm{~K}_{12}[\mathrm{mTHPC}]_{0}-\mathrm{K}_{12}[\mathrm{CD}]_{0}\right)+1 \\
& \mathrm{C}=\mathrm{K}_{11}\left([\mathrm{mTHPC}]_{0}-[\mathrm{CD}]_{0}\right)+1
\end{aligned}
$$

Equation 4. Expression for free guest concentration

Where $\Delta \mathrm{Y}$ - measured signal; $\mathrm{Y}_{\Delta 0}$ - signal from mTHPC molecule; $\mathrm{Y}_{\Delta 1: 1}-$ signal from 1:1 mTHPC/CD complex; $\mathrm{Y}_{\Delta 1: 2}$ - signal from 1:2 mTHPC/CD complex; $\mathrm{K}_{11}$ - binding constant of 1:1 
mTHPC:CD complex; $\mathrm{K}_{12}$ - binding constant of 1:2 mTHPC:CD complex; [CD] - concentration of free $\mathrm{CD} ;[\mathrm{CD}]_{0}$ - total CD concentration; $[\mathrm{mTHPC}]_{0}$ - total mTHPC concentration.

\section{$1.4 \quad$ Molecular modeling}

Molecular dynamics simulations were conducted using the sander module of Amber14 [18]. mTHPC force field was specifically parameterized starting from the Generalized Amber Force Field (GAFF) approach, electrostatic point charges were obtained using the standard RESP procedure [19]. The q4mdCD force field developed by Cézard et al. (2011) was used for heptakis(2,3,6-tri-O-methyl)- $\beta$ cyclodextrin [20]. This potential was developed based on the GLYCAM04 parameters [21-23], modified in a consistent way to take into account substitution at the $-\mathrm{OH}$ groups of a native cyclodextrin.

Classical molecular dynamic simulations were performed at the constant pressure and temperature (NPT) ensemble $(\mathrm{T}=300 \mathrm{~K}, \mathrm{P}=1 \mathrm{~atm})$ for a 1:2 mTHPC:CD complex immersed in TIP3P water (about 18,000 molecules)[24]. The Amber14 default parameters were used for Andersen's temperature coupling scheme and Berendsen's barostat $[25,26]$. Periodic boundary conditions were used throughout the simulation, with long range electrostatics treated by means of the Particle Mesh Ewald (PME) expansion [27].

An equilibration along $500 \mathrm{ps}$ in the NPT ensemble was performed, until reaching a box volume fluctuating around a value corresponding to a cubic box length of $80 \AA$ ( $\pm 8 \AA$ ) and constant energy. We then carried out a simulation run for a total time of $10 \mathrm{~ns}$ using a time step of $1 \mathrm{fs}$. Coordinates were saved every ps for data analysis.

Absorption spectrum was obtained as the convolution of 100 snapshots randomly taken from the MD trajectory. A hybrid QM/MM approach was used with the QM partition constituted by the mTHPC chromophore while CD and water were represented at MM level. Excited state energies were calculated 
at Time Dependent Density Functional Theory (TD-DFT) level using B3LYP as exchange-correlation functional and $6-31+\mathrm{G}^{*}$ basis set, a total of 20 excited states was calculated for each snapshot. QM/MM calculations have been performed by Terachem software interfaced with Amber [28].

\section{Results}

\subsection{Spectral characteristics of $\mathbf{m T H P C} / \boldsymbol{\beta}-\mathrm{CD}$ complexes}

The absorption and fluorescence spectra of mTHPC in buffer solution alone and in the presence of $\beta$-CDs (Hp-, Me-, TM- $\beta-\mathrm{CD})$ are shown in Figures 1 and 2. The significant spectral changes upon the addition of $\beta$-CDs may be ascribed to mTHPC monomerization due to the formation of the inclusion complex. The modification of mTHPC spectral properties appeared to be $\beta$-CD concentrationdependent. At the highest $\beta$-CD concentration $(2 \mathrm{mM})$, no more modifications of mTHPC spectra were observed, indicating the complete binding of mTHPC to $\beta$-CDs (100\% mTHPC loading) (data not shown). Thus, mTHPC spectral characteristics at this concentration of $\beta$-CD could be directly related to the inherent features of inclusion complexes.

The main spectral variations of mTHPC observed due to the formation of the $\mathrm{mTHPC} / \beta-\mathrm{CDs}$ inclusion complexes include:

a) slight changes in the position of $\mathrm{Q}_{4}$ band maximums (shifts about 1-2 nm). The extinction coefficient of the $\mathrm{Q}_{4}$ band significantly increases in the following order: $\mathrm{Hp}-\beta-\mathrm{CD}\left(34700 \mathrm{M}^{-1} \mathrm{~cm}^{-1}\right)<$ $\operatorname{Me}-\beta-C D\left(42700 \mathrm{M}^{-1} \mathrm{~cm}^{-1}\right)<\mathrm{TM}-\beta-\mathrm{CD}\left(54200 \mathrm{M}^{-1} \mathrm{~cm}^{-1}\right)$;

b) alterations in the shape of Soret band and the corresponding $\mathrm{B}$ bands in the fluorescence excitation spectra. The ratio between $B_{x}$ and $B_{y}$ shoulders increases from 0.78 for Hp- $\beta$-CD to 0.97 for TM- $\beta$-CD. A slight bathochromic shift $(2 \mathrm{~nm})$ of the Soret band was observed for mTHPC/Hp- $\beta-\mathrm{CD}$ complexes as compared with other $\beta-C D$ s inclusion complexes; 
c) significant increase of the relative fluorescence quantum yield of mTHPC in TM- $\beta-C D$ and Me- $\beta$ CD complexes, exceeding respectively 0.142 and 0.125 as compared with Hp- $\beta-\mathrm{CD}(0.095)$.

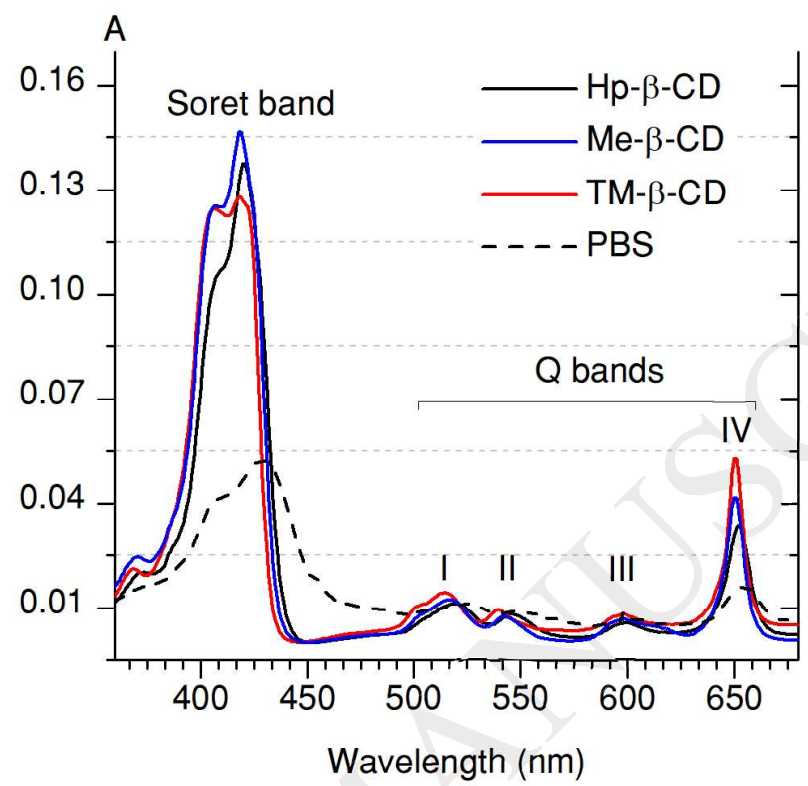

Figure 1. Absorption spectra of $\operatorname{mTHPC}(1 \mu \mathrm{M})$ in DPBS containing $\beta$-CD derivatives $(2 \mathrm{mM})$ : Hp- $\beta-C D$ (black), Me- $\beta-C D$ (blue) and TM- $\beta-C D$ (red). The dotted line indicates mTHPC spectra in DPBS without $\beta$-CDs.
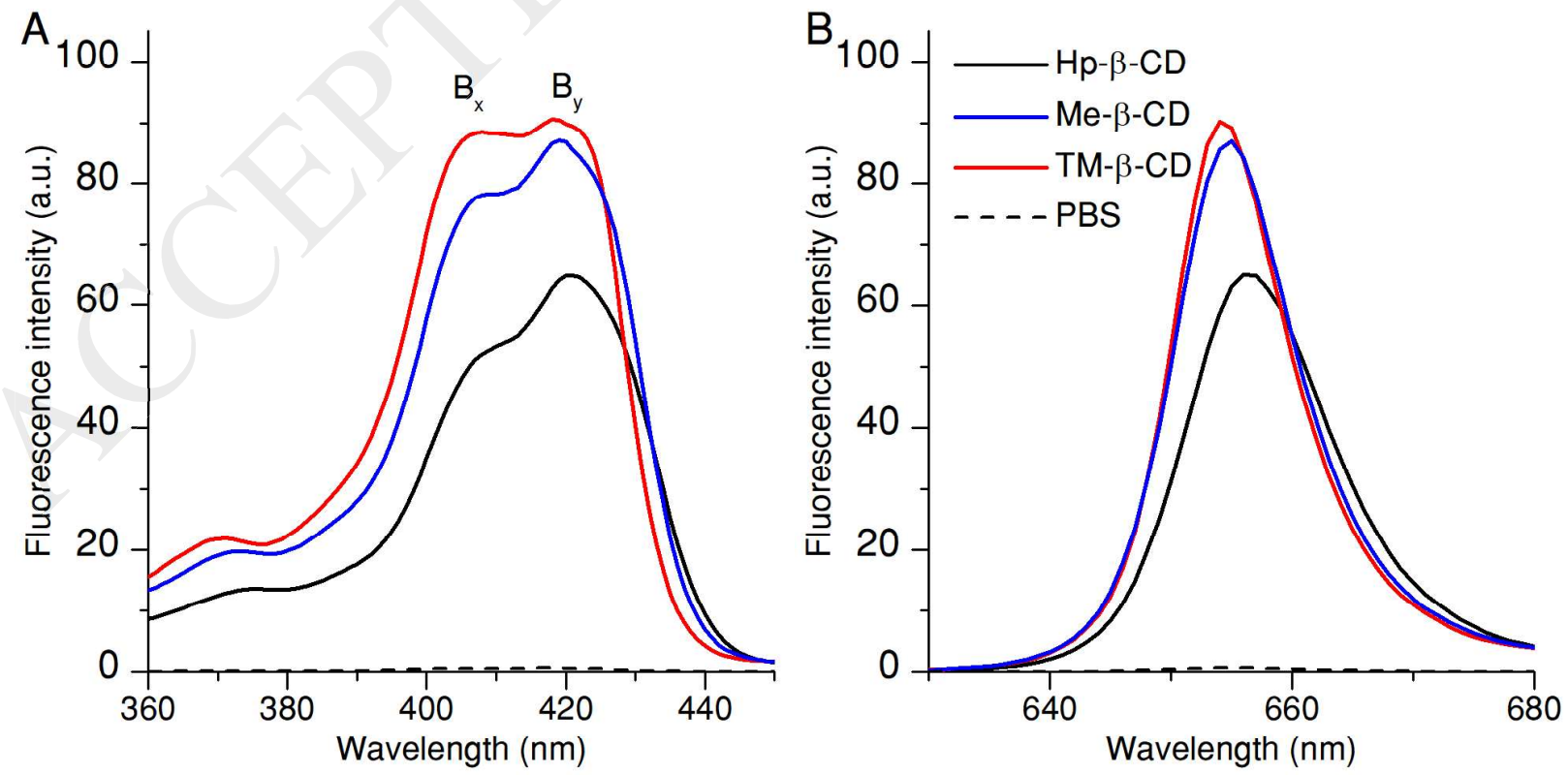
Figure 2. Fluorescence excitation (A) and emission (B) spectra of mTHPC $(1 \mu \mathrm{M})$ in DPBS with $\beta$-CDs (2 mM): Hp- $\beta-C D$ (black), Me- $\beta-C D$ (blue) and TM- $\beta-C D$ (red). The dotted lines indicate mTHPC spectra in DPBS without $\beta$-CDs.

ICD is a widely used technique, complementary to absorption and emission spectroscopy, to characterize of the inclusion complexes formed by $\beta$-CDs. As shown in Figure 3, the interaction of nonabsorbing, chiral $\beta$-CDs, with the optically inactive mTHPC results in the occurrence of ICD signal in mTHPC visible spectral regions. This effect may hence be seen as the direct evidence of the formation of inclusion complexes between mTHPC and $\beta$-CDs. Further, as follows from Figure 3, ICD spectra strongly depend on the type of the host $\beta-\mathrm{CD}$ moiety. In the case of Me- $\beta-\mathrm{CD}$ and Hp- $\beta-\mathrm{CD}$ inclusion complexes, the ICD spectrum of mTHPC consists of two positive maxima that correspond to $\mathrm{B}_{\mathrm{x}}$ and $\mathrm{Q}_{2}$ bands, respectively, and two negative bands assigned to $\mathrm{B}_{\mathrm{y}}$ and $\mathrm{Q}_{4} \mathrm{mTHPC}$ electronic transitions. At the same time, mTHPC binding with TM- $\beta-C D$ results in the occurrence of a strong negative ICD signal at $\mathrm{B}_{\mathrm{y}}$ band position, while other ICD signals are globally much less intense. It should be noted that $\mathrm{Q}_{1}$ and Q3 mTHPC absorption bands do not exhibit ICD activity, probably due to their vibronic nature. 


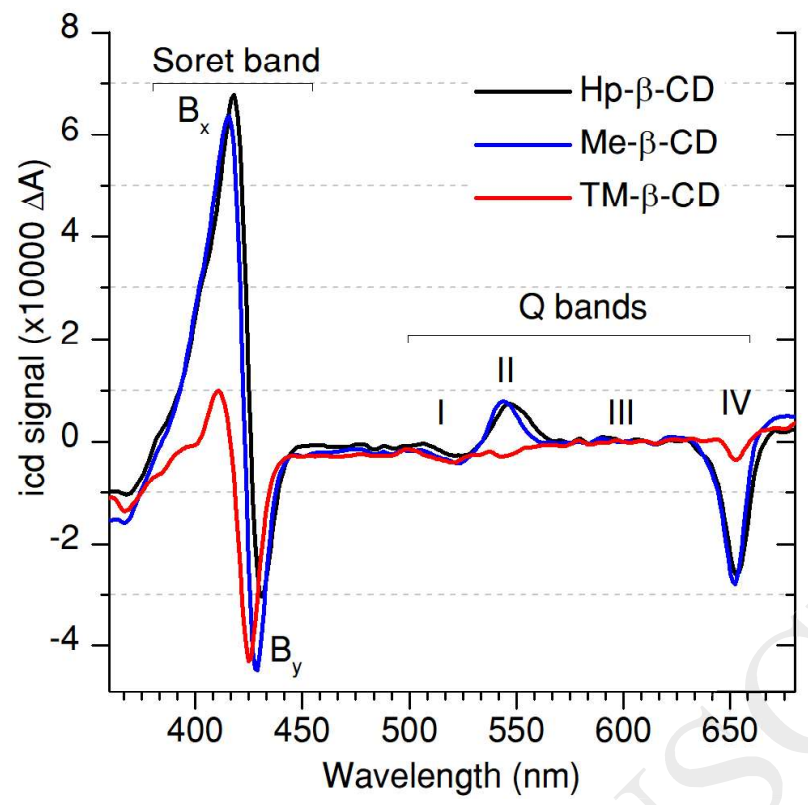

Figure 3. Induced circular dichroism spectra of mTHPC $(1 \mu \mathrm{M})$ in DPBS containing $\beta$-CD derivatives (2 mM): Hp- $\beta-C D$ (black), Me- $\beta-C D$ (blue) and TM- $\beta-C D$ (red).

\subsection{Inclusion complexes binding parameters}

\subsubsection{Stoichiometry}

In order to provide a reasonable mathematical model describing the complex formation from a thermodynamic and kinetic point of view, and in particular to provide the binding constants, it is essential to know the inclusion complex stoichiometry. To determine the stoichiometry of the inclusion complexes, we applied Job's method of continuous variations [29]. In this case, the normalized mTHPC fluorescence intensity, which is directly related to the concentration of the complex, was measured and then plotted as a function of mTHPC molar fraction (Figure 4). For all studied $\beta$-CDs, the maximum fluorescence intensity is detected at the mTHPC molar fraction of $0.30-0.35$ indicating that the most probable mTHPC: $\beta$-CD stoichiometric ratio would be 1:2. 


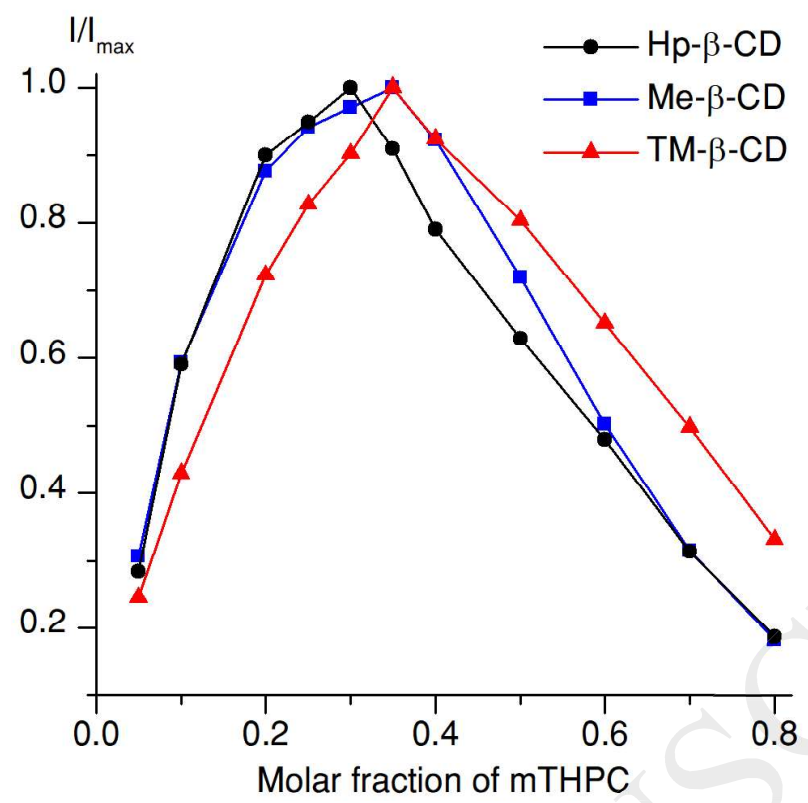

Figure 4. Job's plots of mTHPC/ $\beta-C D$ complexes in DPBS at fluorescence excitation $420 \mathrm{~nm}$. mTHPC fluorescence were measured at $652 \mathrm{~nm}$. The total $\left(C_{\beta-\mathrm{CD}}+C_{\mathrm{mTHPC}}\right)$ concentration was $3 \mu \mathrm{M}$. Molar mTHPC fraction is given by $X_{\mathrm{mTHPC}}=C_{\mathrm{mTHPC}} /\left(C_{\mathrm{mTHPC}}+C_{\beta-\mathrm{CD}}\right)$

We performed classic molecular dynamics (MD) simulations of the 1:2 mTHPC:TM- $\beta-C D$ complex to assess its persistence and evaluate the steric aspects related to its conformation (Figure 5). Indeed, the 1:2 complex was stable all along the MD simulation experiencing very limited variation in the root mean square deviation compared to the starting structure. In addition, the distance between the centers of mass of TM- $\beta-C D$ molecules stays close to $11.3 \AA$ during the MD simulation (Figure 5D). As shown in Figures $5(\mathrm{~A}-\mathrm{C})$ a tri-molecular 1:2 complex is needed to perfectly accommodate the hydrophobic mTHPC porphyrin moiety inside the TM- $\beta$-CD's core. Note also that this arrangement presents no particular steric clashes, while probably constraining the peripheral mTHPC phenyl groups rotation. In addition, the calculated hybrid quantum mechanics/molecular mechanics (QM/MM) absorption spectrum of the mTHPC/ $\beta-\mathrm{CD}$ complex also matches the experimental results with a reasonable accuracy, further confirming the nature of the complex (Figure 5E). 

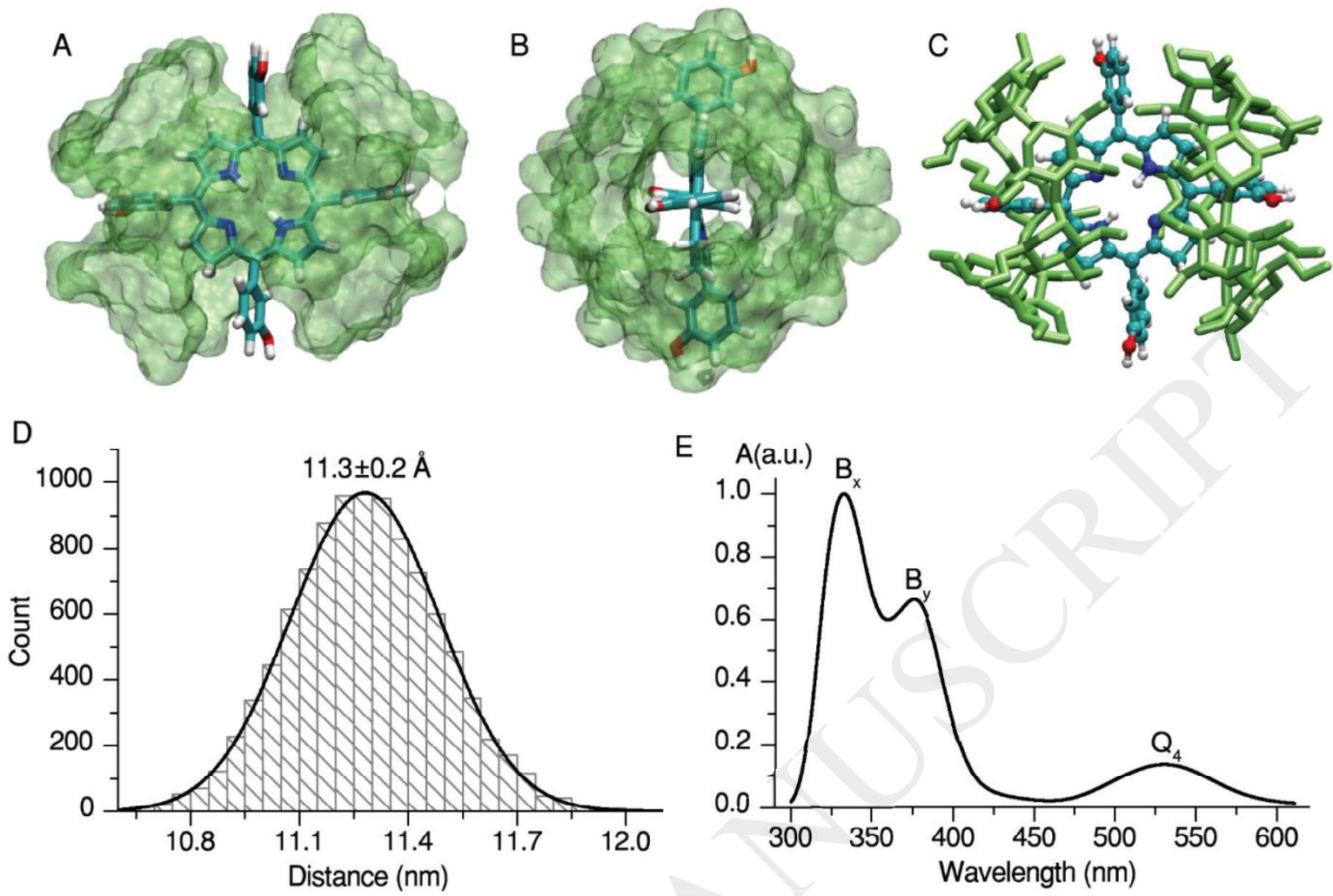

Figure 5. Front (A) and side (B) views of representative snapshot of the mTHPC/TM- $\beta-C D$ complex extracted from the MD simulation. mTHPC is represented in ball and sticks (A-C), while CD occupation is represented with its van der Waals surface $(\mathbf{A}, \mathbf{B})$. Panel $(\mathbf{C})$ provides licorice representation of the complex. (D) Distribution of the distance between the centres of mass of two cyclodextrins in the complex with mTHPC as computed from molecular dynamics simulations. Panel (E) displays the calculated absorption spectrum of the inclusion complex.

\subsubsection{Binding constants}

Among numerous experimental techniques for the determination of binding constants, fluorescence or ICD, possess a high sensitivity to quantify the inclusion complex formation and hence allowing the determination of binding constant value with high accuracy. As an example, the variations of mTHPC fluorescence spectra in water solution upon the increase of $\beta$-CD concentration are presented in Figure 6A. As was mentioned above, mTHPC fluorescence intensity is $\beta$-CD concentration-depended 
and reaches its maximal values for $\mathrm{Me}-\beta-\mathrm{CD}$ concentrations bigger than $0.1 \mathrm{mM}$. Titration curves, obtained for all studied $\beta$-CDs with mTHPC fluorescence at $652 \mathrm{~nm}\left(\lambda_{\text {exc. }}\right.$ at $\left.420 \mathrm{~nm}\right)$, are presented in Figure $6 \mathrm{C}$. The comparison of the binding isotherms for different $\beta-\mathrm{CD}$ derivatives demonstrates that in order to achieve the same fraction of $\mathrm{mTHPC} / \beta-\mathrm{CD}$ complexes, one need to add 10 times less TM- $\beta-\mathrm{CD}$ than Hp- $\beta-C D$ and 3 times less than Me- $\beta-C D$. This fact can obviously be related to the higher affinity of TM- $\beta-C D$ to mTHPC compared with other $\beta$-CDs.

Similar results were obtained by means of ICD approach (Figures 6, B\&D). To plot titration curves for ICD data, we determined the full amplitude of ICD signal as the ratio $\delta A=\Delta A_{\lambda 1}-\Delta A_{\lambda 2}$ to $\delta A_{\max }$, where $\lambda_{1}$ and $\lambda_{2}$ were the wavelengths of ICD spectrum maxima for each mTHPC/ $\beta$-CDs sample. The comparison with fluorescence data showed that the shape and the position of binding isotherms are subjected to changes depending on the experimental technique. However, the affinity in the order TM- $\beta-C D>$ Me- $\beta-C D>$ Hp- $\beta-C D$ persists for both experimental techniques.

To quantify the difference of $\beta$-CDs affinity to mTHPC, we performed a non-linear mathematical fitting analysis of the experimental isotherms using different models: one-step 1:1 and 1:2 models, twostep 1:2 model (Equations 1-3). For calculations we used the assumptions that mTHPC in buffer solution is optically inactive and does not fluoresce $\left(\mathrm{Y}_{\Delta 0}=0\right)$. For two-step 1:2 model, we suggested that the binding of the second $\beta$-CD molecule to MTHPC does not change the mTHPC fluorescence quantum yield and thus $\mathrm{Y}_{\Delta 1: 1}=1, \mathrm{Y}_{\Delta 1: 2}=1$, while binding of each $\beta$-CD molecule results in an equal effect on the ICD spectrum $\left(\mathrm{Y}_{\Delta 1: 1}=0.5, \mathrm{Y}_{\Delta 1: 2}=1\right)$. Moreover, we considered the dependence of free $\beta$-CD on the concentration of "guest" (mTHPC) molecules (see experimental section; Equation 4), according to a previously described protocol [17]. To assess the appropriateness and robustness of our fitting, we considered the adjusted coefficient of determination $\left(r^{2}\right)$. 

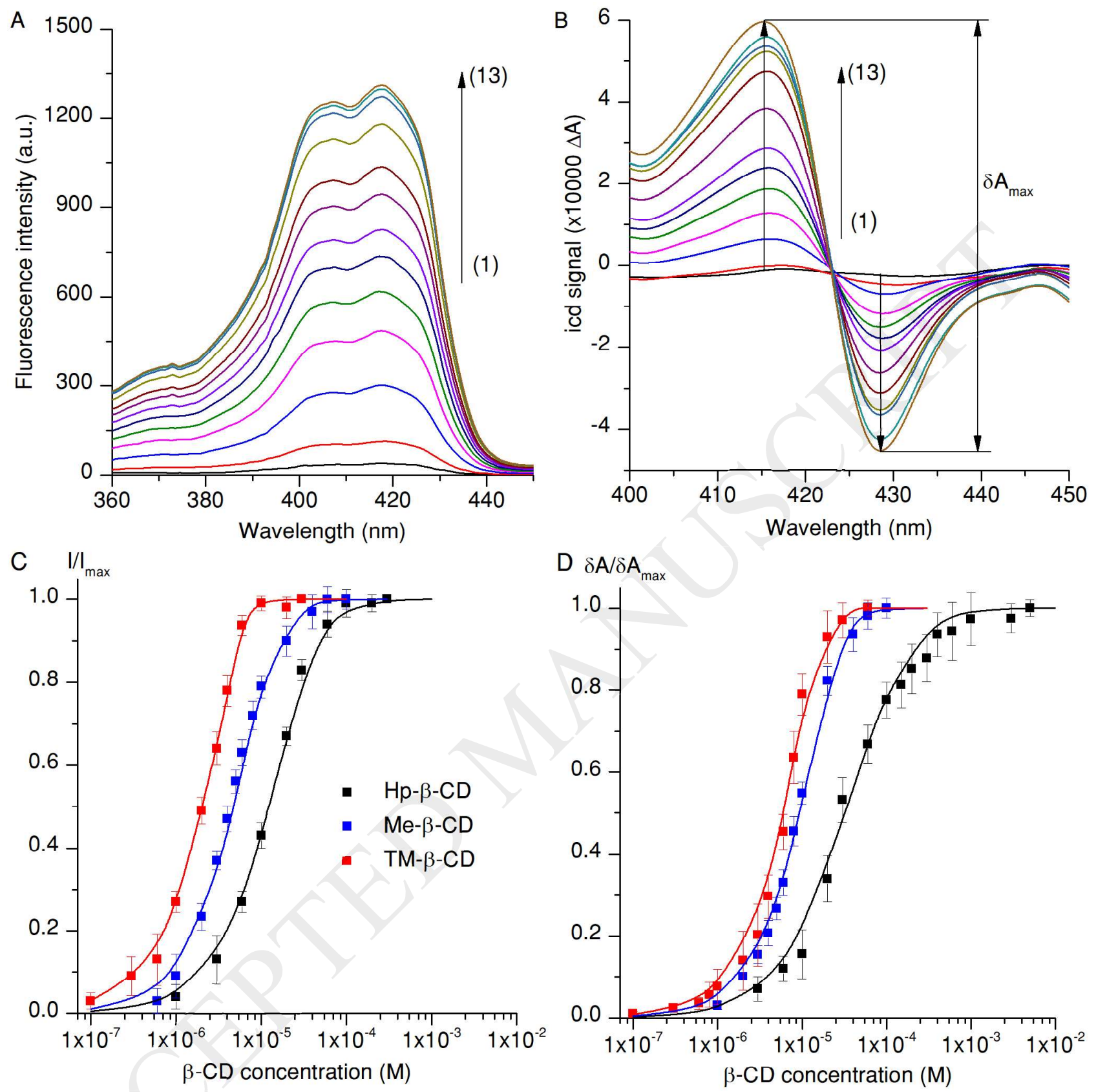

Figure 6. (A) Fluorescence excitation and (B) ICD spectra of mTHPC $(3 \mu \mathrm{M})$ in DPBS containing various amounts of Me- $\beta$-CD. Me- $\beta$-CD concentrations were: $1-0.6 ; 2-1 ; 3-2 ; 4-3 ; 5-4 ; 6-5$; $7-6 ; 8-8 ; 9-10 ; 10-15 ; 11-20 ; 12-40 ; 13-100 \mu \mathrm{M}$. Arrows designate increasing concentration of Me- $\beta$-CD. mTHPC fluorescence was measured at $652 \mathrm{~nm}$. Binding isotherms of $3 \mu \mathrm{M}$ mTHPC upon titration by various $\beta$-CD derivatives in DPBS were obtained by (C) fluorescence and (D) ICD 
techniques. Black (Hp- $\beta-\mathrm{CD})$, blue (Me- $\beta-\mathrm{CD})$ and red (TM- $\beta-\mathrm{CD})$ dots represent the experimental data, while the solid lines are the best fit to an equation for two-step 1:2 model.

According to our calculations, the best agreement is achieved when complex formation is considered as proceeding by a two-step association mechanism $\left(r^{2} \geq 0.98\right)$, compared with one-step $1: 1\left(r^{2} \leq 0.92\right)$ and 1:2 $\left(r^{2} \leq 0.96\right)$ models. Indeed, such model accounts for the simultaneous presence of sufficient amount of both 1:1 as well as 1:2 complexes and hence allow better reproducing of experimental results (Scheme 2). The calculated association constants $\mathrm{K}_{11}$ correspond to the association with one $\beta-\mathrm{CD}$ and $\mathrm{K}_{12}$ represents the association with the second $\beta-\mathrm{CD}$. For a quantitative comparison of $\beta-\mathrm{CD}$ affinity in the case of such stepwise association, the geometrical mean of $\mathrm{K}_{11}$ and $\mathrm{K}_{12}$ constants, $\mathrm{K}=\left(\mathrm{K}_{11} \times \mathrm{K}_{12}\right)^{1 / 2}$ was used. According to the fluorescence data, the obtained $\mathrm{K}$ values were $4.5 \times 10^{4} \mathrm{M}^{-1}, 3.0 \times 10^{5} \mathrm{M}^{-1}$ and 5.6 $\times 10^{6} \mathrm{M}^{-1}$ for Hp-, Me- and TM- $\beta-\mathrm{CD}$, respectively. On the contrary, when taking into account the apparent shift of ICD binding isotherms we obtain lower calculated $\mathrm{K}$ values $\left(2.8 \times 10^{4} \mathrm{M}^{-1}, 2.1 \times 10^{5} \mathrm{M}^{-1}\right.$ and $1.8 \times 10^{6} \mathrm{M}^{-1}$ for Hp-, Me- and TM- $\beta-\mathrm{CD}$, respectively) as compared to the those obtained from fluorescence curves. 


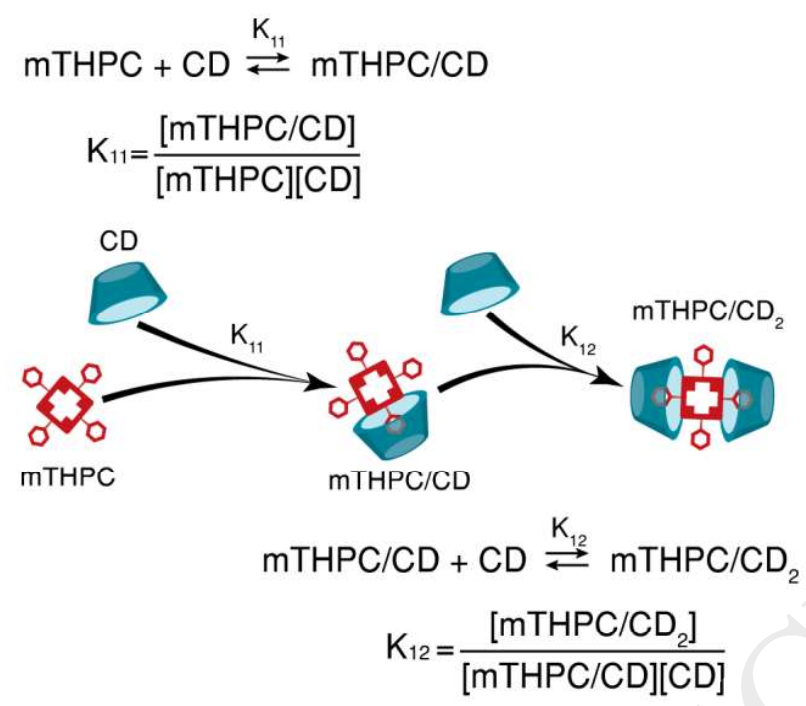

Scheme 2. Schematic representation of the stepwise complex formation between mTHPC and $\beta$-CDs. The association constant $\mathrm{K}_{11}$ corresponds to $1: 1$ complex formation, while $\mathrm{K}_{12}$ is attributed to the association of 1:1 complex with the second $\beta-\mathrm{CD}$ molecule.

\subsection{Influence of mTHPC aggregation on apparent binding constants}

It is worth noting that mTHPC is a highly hydrophobic compound and that self-aggregation of mTHPC molecules ("guest" molecules) should be taken into account since it can affect the inclusion complexes association by decreasing the values of the apparent binding constants [30]. The impact of the aggregation on the estimation of mTHPC/ $\beta$-CDs binding constants is feasible by comparison of the binding isotherms obtained at different mTHPC concentrations. Figure 7A exhibits the dependence of the binding isotherms on mTHPC concentration for the Me- $\beta-C D$. Decreasing the mTHPC concentration shifts the titration curves towards left, i.e. towards the region of lower Me- $\beta$-CD concentrations, hence indicating an apparent increase of the $\beta$-CD's affinity to mTHPC. Similar results were also obtained for TM- and Hp- $\beta-C D$, or when using ICD titrations. However, the application of ICD technique is limited by mTHPC concentration of $1 \mu \mathrm{M}$, while fluorescence technique allows analysing of binding isotherms at much lower "guest" concentrations thus reducing the impact of mTHPC aggregation. 
The quantification of the impact of mTHPC aggregation on the apparent binding constants indeed shows that $\mathrm{K}_{11}$ value significantly depends on mTHPC concentration, while the changes of $\mathrm{K}_{12}$ were random and not significant (data not shown). Therefore, for further calculations we used an average value of $\mathrm{K}_{12}$ as a "correct" binding constant to re-estimate $\mathrm{K}_{11}$ values for various mTHPC concentrations (Table 1). According to our fitting data, $\mathrm{K}_{11}$ value increases with decreasing mTHPC concentration and plateaued at mTHPC concentration less than $10 \mathrm{nM}$ mTHPC (Figure 7B).

Table 1. "Correct" binding constants of mTHPC and $\beta$-CDs

\begin{tabular}{lllll}
\hline & $\mathrm{K}_{11}, \mathrm{M}^{-1}$ & $\mathrm{~K}_{12}, \mathrm{M}^{-1}$ & $\mathrm{~K}, \mathrm{M}^{-1}$ & $\alpha$ \\
\hline Hp- $\beta$-CD & $6.6 \times 10^{5}$ & $4.3 \times 10^{4}$ & $1.7 \times 10^{5}$ & 0.52 \\
Me- $\beta$-CD & $1.1 \times 10^{6}$ & $4.6 \times 10^{5}$ & $7.1 \times 10^{5}$ & 3.35 \\
TM- $\beta$-CD & $3.8 \times 10^{7}$ & $3.1 \times 10^{6}$ & $1.1 \times 10^{7}$ & 0.65 \\
\hline
\end{tabular}
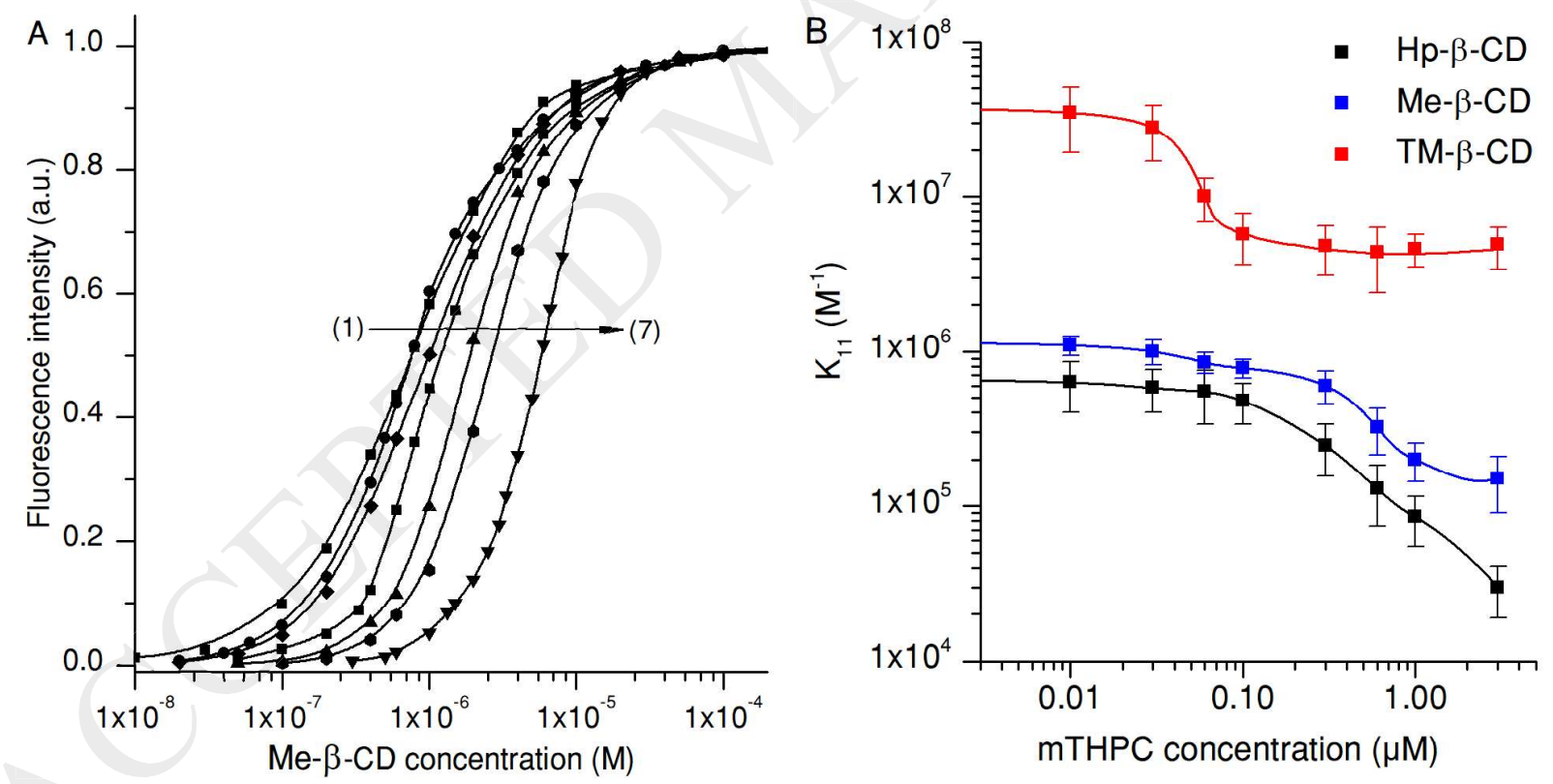

Figure 7. (A) Titration curves by Me- $\beta-\mathrm{CD}$ of mTHPC in different concentrations. mTHPC concentration was: $1-3 ; 2-1 ; 3-0.6 ; 4-0.3 ; 5-0.1 ; 6-0.03 ; 7-0.01 \mu \mathrm{M}$. Arrow designates increasing concentration of mTHPC. (B) Dependence of $\mathrm{K}_{11}$ values on mTHPC concentration. The solid line indicates cubic-spline extrapolation curves. 
The "correct" $\mathrm{K}_{11}$ values (Table 1) were estimated by extrapolation of the curves presented in Figure $7 \mathrm{~B}$, while "correct" $\mathrm{K}_{12}$ values were taken as the average of the values obtained for all the mTHPC concentrations. The extrapolation of $\mathrm{K}_{11} v s$ mTHPC concentration curve was performed in the range of mTHPC concentrations $0.1 \mathrm{nM}-3 \mu \mathrm{M}$, reaching a region where experimental techniques cannot be used due to their sensitivity limits. Moreover, the generalized constants (K) were calculated as a geometrical average of the "correct" $\mathrm{K}_{11}$ and $\mathrm{K}_{12}$ values simplifying the comparison of $\beta$-CD affinity for mTHPC. According to the obtained data, TM- $\beta-C D$ exhibits extremely high affinity $\left(\mathrm{K}=1.1 \times 10^{7} \mathrm{M}^{-1}\right)$, while Me- and $\mathrm{Hp}-\beta-\mathrm{CD}$ are at least 10 times less prone to bind mTHPC $\left(7.1 \times 10^{5} \mathrm{M}^{-1}\right.$ and $1.7 \times 10^{5} \mathrm{M}^{-1}$, respectively). Finally, to emphasize the relationship between $1: 1$ and 1:2 binding constants, cooperativity of binding $(\alpha)$ was estimated as $\alpha=b \times K_{12} / K_{11}$, where $b$ is the statistical coefficient taken equal to 8 considering that it is impossible to distinguish between any of the four 1:1 complexes and two 1:2 complexes [17]. If $\alpha>1$ the system is considered as positive cooperativity; $\alpha<1$ presents negative cooperativity and finally if $\alpha=1$, we conclude on the noncooperative binding. As such, only Me- $\beta$-CD possesses positive binding cooperativity $(\alpha=3.36)$ and stands out from other $\beta$-CD derivatives presenting a slight negative cooperativity $(\alpha=0.56)$.

\section{Discussion}

In the present study we compared the mechanisms of interaction of mTHPC with three $\beta-C D$ derivatives: Hp-, Me- and TM- $\beta-\mathrm{CD}$. The focus of present study was the formation of mTHPC/ $\beta-\mathrm{CDs}$ complexes and quantitative estimation of different $\beta$-CDs affinity for mTHPC, taking into account selfaggregation of mTHPC.

According to the described spectral data (Figures 1-3), all studied cyclodextrins readily interact with mTHPC. The most dramatic mTHPC spectral changes induced by $\beta$-CDs were observed for the relative quantum yield of fluorescence (Figure 2). A similar effect was also observed for other aryl-porphyrins 
and was related to the chromophore monomerization due to the binding with the $\beta$-CDs competing with self-aggregation [31]. For meta-tetraphenyl substituted porphyrins and $\beta$-CD derivatives the typical binding mode can be described as a deep penetration of the porphyrin phenyl rings into the secondary face of the $\beta-C D$, so that a part of the porphyrin moiety in its bound state is located in the $\beta$-CD cavity and is separated from the external solution $[8,14,32]$. Due to the shielding action of $\beta$-CD molecule, the bound porphyrins are not able to form aggregates and hence are stable in monomeric state [31] Similarly, as shown by our data the addition of $\beta$-CDs to the aqueous mTHPC solution prevents PS aggregation, as confirmed by the corresponding changes of mTHPC spectral characteristics. Our proposed mechanism for the formation of inclusion complex is also fully consistent with the appearance of strong ICD effect as a result of the interaction of the optically inactive porphyrin with the chiral CD structure $[4,12,33,34]$.

The alteration of the porphyrin microenvironment upon the complexation affects the photophysical properties of the PS, with the extent of spectroscopic response that depends on the type of lateral substituents $[10,14,32]$. Indeed, $\beta-C D$ interaction with anionic and cationic aryl-porphyrins results in significant shifts of the Soret band as well as in a strong change of the fluorescence emission band $[14,32,33]$. On the contrary, when neutral mTHPC is bound to the $\beta$-CD cavity, only minor changes in the spectral signature are observed (Figures 1-2), most probably due to a less pronounced polarization of the electronic density. Thus, according to our studies, the amplitudes of both ICD and fluorescence emission appear to provide the most reliable tools to analyze the interaction of mTHPC with different $\beta$-CDs (Figure 2-3).

The main quantitative parameters describing the mechanism of formation of the porphyrins/ $\beta-C D$ complexes are the stoichiometry and binding constants. The stoichiometry displays the number of molecules involved in the formation of the complex and determines the binding model, while binding constants reflect the affinity between the complexants [17]. As was mentioned above, the association 
process involves two $\beta$-CDs for one porphyrin due to steric restrictions. We confirmed the 1:2 stoichiometric ratio for all studied $\beta$-CDs by means of Job's plot (Figure 4). This is also in agreement with the results provided earlier and demonstrating that $1: 2$ is the most probable stoichiometry of Me- and Hp- $\beta$-CD complexes with mTHPC [8]. The 1:2 stoichiometric ratio was also confirmed by MD simulation of the mTHPC/TM- $\beta-C D$ complex (Figure 5). It was shown, that TM- $\beta$-CDs molecules tightly interact with mTHPC influencing its conformation and hiding porphyrin molecule from polar solvent. The 1:2 complex was shown to be stable and persistent all along the MD trajectory, and the distances of the center of mass of the $\beta$-CDs moiety were also characterized as extremely stable. QM/MM calculations of the electronic spectra of mTHPC encapsulated in the $\beta$-CDs inclusion complex also supposed the changes in the Soret band shape, observed in the experimental absorption spectra upon complexation with TM- $\beta-\mathrm{CD}$ (Figure 5E).

Taking into account the 1:2 stoichiometric ratio model, a two-step mechanism of complexation was postulated, and the corresponding binding constants have been estimated (Scheme 2). It is obvious, that the 1:2 stoichiometry should not be considered as absolute, and indeed the existence of a 1:1 complex should be taken into account as an intermediate species produced in the complex formation $[14,17]$. The fitting of experimental data by the corresponding mathematical model, which was described in details by Thordarson [17], allows us to quantify the difference in $\beta$-CDs affinity to mTHPC (Figure 6). Both experimental techniques (ICD and fluorescence) demonstrated that TM- $\beta$-CD possesses higher affinity as compared to Me- and Hp- $\beta-\mathrm{CD}$. The moderate deviations in the estimated values of the binding constants obtained from the analysis of ICD or fluorescence spectra may be attributed to the peculiarities of these two techniques. Indeed, while ICD responds to the structural changes induced by the inclusion of mTHPC molecule into the $\beta$-CD cavity, the increase of fluorescence quantum yield is due to the inhibition of mTHPC self-aggregation induced by the complexation with $\beta$-CDs. 
Our numerical estimation of the binding constants for studied $\beta$-CDs without assuming mTHPC aggregation correlates well with similar data previously obtained for various cyclodextrins and mesotetraphenyl substituted porphyrins $[13,14,32,33]$. Concerning mTHPC, there are several studies of Kasselouri and Prognon group on the binding constant values between $\beta$-CD and mTHPC $[8,12,13]$. In the earliest paper Me- $\beta-\mathrm{CD}$ affinity to $\mathrm{mTHPC}$ was lower than that for $\mathrm{Hp}-\beta-\mathrm{CD}[8]$. However, in further reports, they clarified the results using various experimental techniques and association models. In the latest study on this subject, the authors reported binding constants values of $4.8 \times 10^{4} \mathrm{M}^{-1}$ and $1.2 \times 10^{5} \mathrm{M}^{-1}$ for Hp- and Me- $\beta$-CD to mTHPC $(3 \mu \mathrm{M})$ respectively [13]. Our estimations of K correlated well with these data and demonstrated the values of $4.5 \times 10^{4} \mathrm{M}^{-1}, 3.0 \times 10^{5} \mathrm{M}^{-1}$ and $5.6 \times 10^{6} \mathrm{M}^{-1}$ for Hp-, Me- and TM- $\beta-C D$, respectively at mTHPC concentration of $3 \mu \mathrm{M}$.

Even though such data correlate well with the literature, in our opinion they are not sufficient to clearly and fully model the formation of the inclusion complex and to provide the affinity of $\beta$-CDs to mTHPC and related compounds. Indeed, when the guest molecules tend to form aggregates, as it is the case for mTHPC, the competition between aggregation and the formation of the inclusion complexes should lead to changes in the binding isotherms and, as a consequence, to different apparent binding constants. Such effect for a one-step model complexation was theoretically analyzed by Hammelin \& Jullien (1997) [30]. Following their considerations, a decrease in the guest concentration is accompanied by a shift in the equilibrium processes towards the formation of the inclusion complexes hence reducing the impact of the guest aggregation on the measured apparent binding constants. In our experiments, the decrease in the porphyrin concentration was accompanied by a growth of the apparent binding constants values with respect to all the studied $\beta$-CDs (Figure 7). It should be noted that the enhanced apparent binding efficiency of $\beta$-CDs for diluted mTHPC solutions is mainly associated with an increase of the apparent binding constant value for the first $\beta$-CD unit $\left(\mathrm{K}_{11}\right)$, whereas the value of the binding constant of the second $\beta$-CD molecule $\left(\mathrm{K}_{12}\right)$ remains almost unchanged. Such a difference in the 
behavior of the $\mathrm{K}_{11}$ and $\mathrm{K}_{12}$ apparent constants can be attributed to the changes in the guest solubility as a result of its interaction with $\beta$-CDs. Indeed, the binding of even a single $\beta$-CD molecule should significantly reduce mTHPC aggregation potential, hence reducing the influence of aggregation processes on the formation of inclusion complexes.

Extrapolation of the dependence of the $\mathrm{K}_{11}$ and $\mathrm{K}_{12}$ binding constants in the range of the smallest mTHPC concentrations allowed us to compare correct affinities of the studied $\beta$-CDs to the PS. TM- $\beta-C D$ is characterized by the greatest affinity to $\mathrm{mTHPC}$, the corrected $\mathrm{K}$ value for this cyclodextrin exceeds $10^{7} \mathrm{M}^{-1}$. For Hp- and Me- $\beta-\mathrm{CD}$ the binding constants are equal to $1.1 \times 10^{5} \mathrm{M}^{-1}$ and $7.1 \times 10^{5} \mathrm{M}^{-1}$ respectively. It should be noted that such significant difference in the binding constants cannot be attributed to physical-chemical peculiarities such as solubility or aggregation of the cyclodextrins themselves. According to the work of Hammelin \& Jullien (1997) [30], a change in the properties of the host molecules should not modify the isotherms of the inclusion complexes formation.

Our data demonstrate that complete methylated derivative (TM- $\beta-\mathrm{CD}$ ) possesses the highest affinity to mTHPC among all studied $\beta$-CDs. According to the previous reports, the strong affinity of TM- $\beta$-CD to aryl-porphyrins is anticipated [14,36,37]. The formation of inclusion complex deals with the conformation changes of both TM- $\beta-C D$ and porphyrin molecules due to the optimization of intermolecular interactions [14]. The complete methylation of $\beta$-CD contributes to the increase of flexibility of CD's core due to the absence of intramolecular hydrogen bonds between the secondary $\mathrm{OH}$ groups of $\beta-\mathrm{CD}$ glucopyranose units [38,39]. The complete methylated $\beta$-CDs exhibit highly hydrophobic cavity leading to the deeper encapsulation of mTHPC as well as stronger interaction with mTHPC phenol substitutes limiting the peripheral mTHPC phenyl groups rotation [14,37]. Similar features of inclusion association were demonstrated during the MD calculation of $\mathrm{mTHPC} / \mathrm{TM}-\beta-\mathrm{CD}$ complex. In the case of Hp- $\beta-\mathrm{CD}$, long hydroxypropyl chains prevent rapprochement of mTHPC and Hp- $\beta$-CD molecules, significantly decreasing affinity compared with methylated $\beta$-CD derivatives. 
Beside the quantitative characterization of $\beta-\mathrm{CD}$ and mTHPC inclusion complex formation, our results provide strong evidence suggesting the applicability of $\beta$-CDs as vectors for mTHPC-based PDT. The value of $\beta-C D$ binding constant to mTHPC plays a key role in the case of co-administration of mTHPC with $\beta$-CDs. Depending on the type of $\beta$-CDs, we observed a different extent of the influence $\beta$ CDs on various stages of mTHPC biodistribution in tumor-bearing mice [7]. Methylation of $\beta$-CDs increases their affinity to MTHPC providing significant acceleration of PS transport to the target tissues and alterations in the biodistribution of mTHPC among different organs and tissues. In the present work, TM- $\beta-C D$ was introduced as a new component possessing much higher affinity to mTHPC compared with previously studied compounds (Me- and Hp- $\beta-\mathrm{CD}$ ). Thus, according to our calculations, we can suppose that TM- $\beta-C D$ could be a potent vector for the alteration of the biodistribution profile of mTHPC-based PDT.

\section{Conclusions}

In the present work, we experimentally assessed the binding affinity of three $\beta$-CD derivatives to mTHPC. The results obtained are in a good agreement with the previous reports on the interaction of $\beta$ CD with aryl-porphyrins and complete the data array about the inclusion complex formation mechanisms. The estimated binding constant values confirmed a high affinity of $\beta$-CD to mTHPC. Moreover, the accurate assumption of mTHPC self-aggregation effects in our model resulted in significantly higher values than previously reported. As a corollary of our results concerning the high binding affinity and efficient solubilization of mTHPC by $\beta-C D$, one can assume the application of $\beta$ CDs as mTHPC nanovectors. Thus, the knowledge of correct values of binding constants could be helpful for the selection of optimal composition of $\beta$-CD-based delivery system for mTHPC-mediated PDT. 


\section{Acknowledgments}

This work was supported by the Institut de Cancérologie de Lorraine; French "Ligue Nationale Contre le Cancer (CCIR-GE)"; Belarusian Republican Foundation for Fundamental Research (BRFFR) [grant numbers M17MC-028; M18MB-002; 517-106]; the Ministry of Education of the Republic. The authors thank biolitec research GmbH (Jena, Germany) for providing with mTHPC and Alexandre Kriznik (Platform of Biophysics and Structural Biology of UMS 2008 IBSLor, UL-CNRS-INSERM) for circular dichroism facilities access.

\section{References}

[1] M.O. Senge, mTHPC - A drug on its way from second to third generation photosensitizer?, Photodiagnosis Photodyn. Ther. 9 (2012) 170-179. doi:10.1016/j.pdpdt.2011.10.001.

[2] M.O. Senge, J.C. Brandt, Temoporfin (Foscan ${ }^{\circledR}$, 5,10,15,20-tetra(m-hydroxyphenyl)chlorin)--a second-generation photosensitizer, Photochem. Photobiol. 87 (2011) 1240-1296. doi:10.1111/j.1751-1097.2011.00986.x.

[3] D. Kachatkou, S. Sasnouski, V. Zorin, T. Zorina, M.-A. D'Hallewin, F. Guillemin, L. Bezdetnaya, Unusual photoinduced response of mTHPC liposomal formulation (Foslip), Photochem. Photobiol. 85 (2009) 719-724. doi:10.1111/j.1751-1097.2008.00466.x.

[4] J. Mosinger, L. Slavětínská, K. Lang, P. Coufal, P. Kubát, Cyclodextrin carriers of positively charged porphyrin sensitizers, Org. Biomol. Chem. 7 (2009) 3797. doi:10.1039/b908772a.

[5] H. Kolárová, M. Huf, J. Macedek, P. Nevrelová, M. Tomecka, R. Bajgar, J. Mosinger, M. Strnad, The cellular uptake of sensitizers bound to cyclodextrin carriers, Acta Medica Hradec Král. Univ. Carol. Fac. Medica Hradec Král. 47 (2004) 313-315.

[6] K.T. Arun, D.T. Jayaram, R.R. Avirah, D. Ramaiah, $\beta$-Cyclodextrin as a photosensitizer carrier: effect on photophysical properties and chemical reactivity of squaraine dyes, J. Phys. Chem. B. 115 (2011) 7122-7128. doi:10.1021/jp201784b.

[7] I. Yankovsky, E. Bastien, I. Yakavets, I. Khludeyev, H.-P. Lassalle, S. Gräfe, L. Bezdetnaya, V. Zorin, Inclusion complexation with $\beta$-cyclodextrin derivatives alters photodynamic activity and biodistribution of meta-tetra(hydroxyphenyl)chlorin, Eur. J. Pharm. Sci. Off. J. Eur. Fed. Pharm. Sci. 91 (2016) 172-182. doi:10.1016/j.ejps.2016.06.012.

[8] D. Demore, A. Kasselouri, O. Bourdon, J. Blais, G. Mahuzier, P. Prognon, Enhancement of 5,10,15,20-Tetra(m-Hydroxyphenyl)chlorin Fluorescence Emission by Inclusion in Natural and Modified Cyclodextrins, Appl. Spectrosc. 53 (1999) 523-527.

[9] I. Yakavets, I. Yankovsky, M. Millard, L. Lamy, H.-P. Lassalle, A. Wiehe, V. Zorin, L. Bezdetnaya, The alteration of temoporfin distribution in multicellular tumor spheroids by $\beta$ cyclodextrins, Int. J. Pharm. 529 (2017) 568-575. doi:10.1016/j.ijpharm.2017.07.037.

[10] I. Yakavets, I. Yankovsky, L. Bezdetnaya, V. Zorin, Soret band shape indicates mTHPC distribution between $\beta$-cyclodextrins and serum proteins, Dyes Pigments. 137 (2017) 299-306. doi:10.1016/j.dyepig.2016.11.007.

[11] V.J. Stella, Q. He, Cyclodextrins, Toxicol. Pathol. $36 \quad$ (2008) 30-42. doi:10.1177/0192623307310945. 
[12] M.-C. Desroches, A. Kasselouri, O. Bourdon, P. Chaminade, J. Blais, P. Prognon, A direct sensitized fluorimetric determination of5,10,15,20-tetra(m-hydroxyphenyl)chlorin [m-

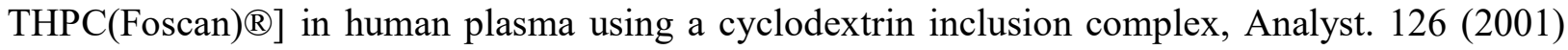
923-927. doi:10.1039/B100808K.

[13] A. Bautista-Sanchez, A. Kasselouri, M.-C. Desroches, J. Blais, P. Maillard, D.M. de Oliveira, A.C. Tedesco, P. Prognon, J. Delaire, Photophysical properties of glucoconjugated chlorins and porphyrins and their associations with cyclodextrins, J. Photochem. Photobiol. B. 81 (2005) 154 162. doi:10.1016/j.jphotobiol.2005.05.013.

[14] K. Kano, R. Nishiyabu, T. Asada, Y. Kuroda, Static and Dynamic Behavior of 2:1 Inclusion Complexes of Cyclodextrins and Charged Porphyrins in Aqueous Organic Media, J. Am. Chem. Soc. 124 (2002) 9937-9944. doi:10.1021/ja020253n.

[15] R. Bonnett, P. Charlesworth, B.D. Djelal, S. Foley, D.J. McGarvey, T.G. Truscott, Photophysical properties of 5,10,15,20-tetrakis(m-hydroxyphenyl)porphyrin (m-THPP), 5,10,15,20-tetrakis(mhydroxyphenyl)chlorin (m-THPC) and 5,10,15,20-tetrakis(m-hydroxyphenyl)bacteriochlorin (mTHPBC): a comparative study, J. Chem. Soc. Perkin Trans. 2. (1999) 325-328. doi:10.1039/A805328F.

[16] E.M.M. Del Valle, Cyclodextrins and their uses: a review, Process Biochem. 39 (2004) 1033-1046. doi:10.1016/S0032-9592(03)00258-9.

[17] P. Thordarson, Determining association constants from titration experiments in supramolecular chemistry, Chem Soc Rev. 40 (2011) 1305-1323. doi:10.1039/C0CS00062K.

[18] D.A. Case, V. Babin, J. Berryman, R.M. Betz, Q. Cai, D.S. Cerutti, C. Iii, T. E, T.A. Darden, R.E. Duke, H. Gohlke, A.W. Goetz, S. Gusarov, N. Homeyer, P. Janowski, J. Kaus, I. Kolossváry, A. Kovalenko, T.S. Lee, S. LeGrand, T. Luchko, R. Luo, B. Madej, K.M. Merz, F. Paesani, D.R. Roe, A. Roitberg, C. Sagui, R. Salomon-Ferrer, G. Seabra, C.L. Simmerling, W. Smith, J. Swails, R.C. Walker, J. Wang, R.M. Wolf, X. Wu, P.A. Kollman, Amber 14, (2014). http://orbilu.uni.lu/handle/10993/16614 (accessed February 15, 2018).

[19] Wang Junmei, Cieplak Piotr, Kollman Peter A., How well does a restrained electrostatic potential (RESP) model perform in calculating conformational energies of organic and biological molecules?, J. Comput. Chem. 21 (2000) 1049-1074. doi:10.1002/1096987X(200009)21:12<1049::AID-JCC3>3.0.CO;2-F.

[20] C. Cézard, X. Trivelli, F. Aubry, F. Djedaïni-Pilard, F.-Y. Dupradeau, Molecular dynamics studies of native and substituted cyclodextrins in different media: 1. Charge derivation and force field performances, Phys. Chem. Chem. Phys. 13 (2011) 15103-15121. doi:10.1039/C1CP20854C.

[21] K.N. Kirschner, R.J. Woods, Solvent interactions determine carbohydrate conformation, Proc. Natl. Acad. Sci. 98 (2001) 10541-10545. doi:10.1073/pnas.191362798.

[22] M. Basma, S. Sundara, D. Çalgan, T. Vernali, R.J. Woods, Solvated ensemble averaging in the calculation of partial atomic charges, J. Comput. Chem. 22 (2001) 1125-1137. doi:10.1002/jcc.1072.

[23] K.N. Kirschner, R.J. Woods, Quantum Mechanical Study of the Nonbonded Forces in Water-Methanol Complexes, J. Phys. Chem. A. 105 (2001) 4150-4155. doi:10.1021/jp004413y.

[24] W.L. Jorgensen, J. Chandrasekhar, J.D. Madura, R.W. Impey, M.L. Klein, Comparison of simple potential functions for simulating liquid water, J. Chem. Phys. 79 (1983) 926-935. doi:10.1063/1.445869.

[25] T.A. Andrea, W.C. Swope, H.C. Andersen, The role of long ranged forces in determining the structure and properties of liquid water, J. Chem. Phys. 79 (1983) 4576-4584. doi:10.1063/1.446373.

[26] H.J.C. Berendsen, J.P.M. Postma, W.F. van Gunsteren, A. DiNola, J.R. Haak, Molecular dynamics with coupling to an external bath, J. Chem. Phys. 81 (1984) 3684-3690. doi:10.1063/1.448118. 
[27] U. Essmann, L. Perera, M.L. Berkowitz, T. Darden, H. Lee, L.G. Pedersen, A smooth particle mesh Ewald method, J. Chem. Phys. 103 (1995) 8577-8593. doi:10.1063/1.470117.

[28] D.A. Case, J.T. Berryman, R.M. Betz, D.S. Cerutti, T.E. Cheatham, T.A. Darden, R.E. Duke, T.J. Giese, H. Gohlke, A.W. Goetz, N. Homeyer, S. Izadi, P. Janowski, J. Kaus, A. Kovalenko, T.S. Lee, S. LeGrand, P. Li, T. Luchko, R. Luo, B. Madej, G. Monard, K.M. Merz, F. Paesani, D.R. Roe, A. Roitberg, C. Sagui, R. Salomon-Ferrer, G. Seabra, C.L. Simmerling, W. Smith, J. Swails, R.C. Walker, J. Wang, X. Wu, R.M. Wolf, P.A. Kollman, Amber 15, Univ. Calif. San Franc. (2015).

[29] W. Likussar, D.F. Boltz, Theory of continuous variations plots and a new method for spectrophotometric determination of extraction and formation constants, Anal. Chem. 43 (1971) 1265-1272. doi:10.1021/ac60304a006.

[30] B. Hamelin, L. Jullien, Does aggregation modulate the apparent association constant of host-guest complexes and related species?, J. Chem. Soc. Faraday Trans. 93 (1997) 2153-2160. doi:10.1039/A700730B.

[31] J.-J. Wu, H.-L. Ma, H.-S. Mao, Y. Wang, W.-J. Jin, Investigation on disassociation of porphyrin Jaggregates induced by $\beta$-cyclodextrins using absorption and fluorescence spectroscopy, J. Photochem. Photobiol. Chem. 173 (2005) 296-300. doi:10.1016/j.jphotochem.2005.04.008.

[32] J. Mosinger, V. Kliment, J. Sejbal, P. Kubát, K. Lang, Host-guest complexes of anionic porphyrin sensitizers with cyclodextrins, J. Porphyr. Phthalocyanines. 06 (2002) 514-526. doi:10.1142/S1088424602000646.

[33] S. Hamai, T. Koshiyama, Electronic absorption, fluorescence, and circular dichroism spectroscopic studies on the inclusion complexes of tetrakis(4-sulfonatophenyl)porphyrin with cyclodextrins in basic aqueous solutions, J. Photochem. Photobiol. Chem. 127 (1999) 135-141. doi:10.1016/S10106030(99)00144-6.

[34] I.V. Yakavets, I.V. Yankovsky, I.I. Khludeyev, H.P. Lassalle, L.N. Bezdetnaya, V.P. Zorin, Optical Methods for the Analysis of the Temoprofin Photosensitizer Distribution Between Serum Proteins and Methyl- $\beta$-Cyclodextrin Nanocarriers in Blood Serum, J. Appl. Spectrosc. 84 (2018) 1030-1036. doi:10.1007/s10812-018-0582-z.

[35] K. Kano, R. Nishiyabu, T. Yamazaki, I. Yamazaki, Convenient Scaffold for Forming Heteroporphyrin Arrays in Aqueous Media, J. Am. Chem. Soc. 125 (2003) 10625-10634. doi: $10.1021 / \mathrm{ja} 035055 \mathrm{q}$.

[36] T. Carofiglio, R. Fornasier, V. Lucchini, C. Rosso, U. Tonellato, Very strong binding and mode of complexation of water-soluble porphyrins with a permethylated $\beta$-cyclodextrin, Tetrahedron Lett. 37 (1996) 8019-8022. doi:10.1016/0040-4039(96)01814-X.

[37] W. Saenger, Cyclodextrin Inclusion Compounds in Research and Industry, Angew. Chem. Int. Ed. Engl. 19 (1980) 344-362. doi:10.1002/anie.198003441.

[38] K. Harata, K. Uekama, M. Otagiri, F. Hirayama, Crystal structures of cyclodextrin complexes with chiral molecules, J. Incl. Phenom. 2 (1984) 583-594. doi:10.1007/BF00662224. 